\title{
Applications of free circulating nucleic acids in clinical medicine: Recent advances
}

\author{
A.S.M. Giasuddin ${ }^{1}$, Khadija Akther Jhuma ${ }^{1}$ and A.M. Mujibul $\mathrm{Haq}^{2}$ \\ Department of ${ }^{1}$ Biochemistry and ${ }^{2}$ Medicine, Medical College for Women and Hospital, Uttara Model \\ Town, Dhaka 1230, Bangladesh.e-mail:medicalcollegeforwomen@yahoo.com
}

\begin{abstract}
The objective of this review article was to highlight briefly the recent advances made relevant to applications of free circulating nucleic acids (FcNAs) in clinical medicine. Detection of FcNAs in plasma, serum and other body fluids from healthy subjects as well as in patients has opened up the possibility of diagnosis and monitoring of diseases. With the rapid developments in molecular biology techniques such as real-time quantitative polymerase chain reaction (rt-qPCR), quantitative methylation specific PCR (qMS-PCR), matrix-assisted laser desorption/ionization time of flight (MALDI-ToF) mass spectrometry, quantitative fluorescent PCR (QF-PCR), single allele primer extension reaction (SAPER) method and other techniques the applications in clinical medicine have increased. The recent discovery of epigenetic changes in placental/fetal DNA and the detection of fetal/placental-specific RNAs have made FcNAs to be used for diagnosis of genetic disorders in all pregnancies irrespective of the gender of the fetus in early intrauterine life. It is now possible to detect very small amounts of, and specific mutations in, fetal DNA in the presence of excess non-specific maternal DNA. In oncology, detection and monitoring of tumors are now possible by the detection of tumor-derived FcNAs. In other conditions, such as diabetes mellitus, trauma and stroke FcNAs have been shown to be useful also. In spite of these advances questions regarding the origin and biologic significance of FcNAs remain to be answered. Standardization of methodologies including pre-analytical and analytical aspects will revolutionize the applications of FcNAs in the diagnosis and monitoring of diseases in clinical medicine in the next few years.
\end{abstract}

\section{Introduction}

All eukaryotic cells have double-stranded deoxyribonucleic acid (dsDNA) and different classes of ribonucleic acid (RNA). Based on Watson and Crick's outstanding discovery of the three dimentional molecular structure of dsDNA in 1953, many more fundamental discoveries have been made subsequently such as the genetic disorder in 1956, genetic code in 1961-66, genetic engineering in 1970-73, DNA sequencing in 1970s, monoclonal antibodies (hybridoma technology) in 1975, DNA fingerprinting in 1984, gene therapy in 1990 and human genome project (HGP) in 2003. These discoveries have revolutionalized the biomedical sciences and hence applications in clinical medicine ${ }^{1-4}$. When in 2001, with the sequencing of the human genome, the sequencing projects of many organisms reached a summit, there was no doubt among the scientific community that nothing in the near future would be as spectacular. It was called one of the biggest milestones of the $21^{\text {st }}$ century, and the most important achievement in biology. However, this excitement did not last long. Already in the same year, the discovery of ribonucleic acid interference (RNAi) in mammals created a similar hype, which is now experiencing explosive growth ${ }^{5,6}$. When researchers come upon an unexpected but fundamental biological mechanism, it can define a scientific era. We are now experiencing another such period of dramatic breakthroughs, this time with the discovery focused on free circulating nucleic acids (FcNAs) in plasma/serum as $\operatorname{diagnostics}^{7,8}$.

This discovery of nucleic acids in plasma and serum in healthy subjects as well as in ill patients was made by Mandel and Metais in 1947 before 
Watson and Crick described the helical structure of the dsDNA ${ }^{7,8}$. This discovery of nucleic acids in plasma and serum was forgotten until the 1960s, when it was shown that patients with systemic lupus erythematosus (SLE) had higher levels of circulating $\mathrm{DNA}^{9}$. In 1970, it was shown that increased levels of DNA in circulation could be detected in other diseases, such as rheumatoid arthritis, glomerular nephritis, pancreatitis, inflammatory bowel disease, and hepatitis ${ }^{10}$. This was followed by the discovery of higher concentration of circulating DNA in patients with cancer compared to patients without cancer ${ }^{11}$. Recently, it was shown that concentration of circulating DNA was higher in patients with metastases compared to patients with localized disease and that the circulating DNA concentration decreased by up to $90 \%$ following radiotherapy ${ }^{11}$. Stroun and Anker showed that certain characteristics of tumor DNA were also present in circulating $\mathrm{DNA}^{12}$. The next major breakthrough in the field of FcNAs was the discovery of fetal DNA in maternal plasma by Lo et $\mathrm{al}^{13}$. This opened up a new field of investigation of noninvasive prenatal diagnosis using FcNAs in maternal blood with quantitative polymerase chain reaction (rt-qPCR), quantitative methylation specific PCR (qMS-PCR), matrix-assisted laser desorption/ionization time of flight (MALDI-ToF) mass spectrometry, quantitative fluorescent PCR (QF-PCR), single allele primer extension reaction (SAPER) method and other techniques. Measurement of circulating fetal DNA in maternal plasma has been used as a noninvasive method for fetal gender determination, assessing chromosome ploidy and monitoring various pregnancy-related complications recently. Some of these recent developments in the applications of FcNAs in the diagnosis and monitoring of diseases in clinical medicine are briefly highlighted in this review article.

\section{Biology of FcNAs}

In a series of elegant experiments, Stroun and coworkers showed that DNA circulates in the free form, which can enter somatic and reproductive cells. Further experiments showed that the DNA released from living cells was accompanied by DNA polymerase and that there seemed to be preferential release of newly synthesized $\mathrm{DNA}^{14}$. These early studies showed the presence of circulating nucleic acids in the free form and that they have the potential to initiate synthesis of $\mathrm{RNA}^{15}$. One of the functions of circulating DNA may be to act as a messenger between cells and tissues within the organism ${ }^{14}$. In addition to DNA, it is known that RNA can be detected in the circulation. It is now well documented that RNA can be detected in plasma, serum, and other body fluids, as well as from cell-free supernatants of in vitro cultivated cells. The RNA appears to be complexed with other molecules, making it resistant to digestion by ribonuclease $^{16}$. The mechanism by which RNA is released into the circulation is still not clear. Possible mechanisms suggested are an active process and a non-specific release from apoptotic or necrotic cells. Like DNA, RNA in the circulation can also be taken up by other cells. Over the past several years messenger RNA detected in the circulation includes fetal genes in the circulation of pregnant women, housekeeping genes in healthy persons as well as in patients with disease, and genes over expressed in a variety of tumors ${ }^{17}$. In spite of such a large literature on circulating RNA, the biological significance of circulating RNA is not yet known. Measurement of circulating messenger RNA has been used in the field of oncology as possible tumor markers and in the field of fetal medicine to detect fetal abnormalities and pregnancy complications. However, the full potential of measurement of circulating RNA in circulation is yet to be realized and this will depend on new methods and further diagnostic work.

\section{FcNAs in fetal medicine}

Since the discovery of fetal nucleic acids in maternal plasma there have been a large number of publications on the possible applications and the significance of fetal nucleic acids. Bianchi and coworkers have examined in detail the effect of gestational age, race, parity, smoking history, and type of conception (natural or assisted). They showed that gestational age is a significant factor affecting fetal DNA levels. Fetal DNA levels increase by about $21 \%$ per week in the first trimester ${ }^{18}$. Smoking and maternal age have no influence on fetal DNA concentrations; however, there was a significant inverse correlation between maternal weight and fetal DNA levels ${ }^{19}$. There was a difference in the fetal DNA levels according to the type of conception ${ }^{20}$. Most of the studies on fetal DNA are based on the detection of Y chromosome signal in the presence of a male fetus.

Lo and co-workers have recently shown that hypomethylated mapsin gene, the first universal fetal epigenetic marker, can be used for fetal DNA detection in maternal plasma, irrespective of fetal gender and genetic polymorphisms. This marker may catalyze the eventual clinical use of circulating fetal DNA for noninvasive prenatal diagnosis, such as for the detection of fetal chromosomal aneuploidies $^{21,22}$. Poon et al showed that a region of mapsin DNA, which is methylated if inherited 
from the father, and unmethylated if inherited from the mother, could be used to differentiate fetal origin of DNA in circulation ${ }^{23}$. These workers then went on to show that the maspin gene is hypomethylated in the placenta, but hypermethylated in maternal blood cells ${ }^{24}$. Hypomethylated maspin sequences were shown to be present in the plasma of pregnant women and this was rapidly cleared after delivery. The concentration of hypomethylated maspin DNA in the circulation was elevated nearly six times in the plasma of women suffering from pre-eclampsia, showing that hypomethylated maspin DNA could be a very useful fetal marker. This has opened up a new field of noninvasive prenatal diagnosis that can be applied to all pregnancies.

Another approach to detect fetal cell-free DNA in maternal plasma is to examine the size. Li et al., have shown that fetal cell-free DNA is smaller than comparable maternal cell-free DNA molecules ${ }^{25}$. They extracted DNA from maternal plasma and subjected it to gel electrophoresis. Following gel electrophoresis they carefully sliced discreet fragments of different sizes and examined the fragments for fetal DNA using the SRY locus. This showed that the majority of fetal DNA had a molecular size of less than $300 \mathrm{bp}$ whereas most of the maternal DNA was greater than $300 \mathrm{bp}$. This finding suggests that fetal cell-free DNA could be enriched on the basis of its size. The applicability of this to clinical diagnosis was shown by the ability to detect achrondroplasia and $\beta$-thalassemia prenatally $^{26}$. By isolating the cell-free DNA from maternal plasma according to size and using an allele-specific rt-qPCR-based approach, they demonstrated the feasibility of detecting $\beta$ thalassemia in maternal plasma ${ }^{25,26}$. Fetal DNA has been successfully used in the fetal blood group genotyping. Daniels et al. have shown that by using fetal DNA in maternal plasma Rh status of the fetus can be successfully determined. Using rt-qPCR, they were able to detect $\mathrm{RhD}$ exons 4, 5, and 10 . This technique is greater than $99 \%$ accurate in detecting $\mathrm{Rh}$ status of the fetus according to experience from the National Blood Group Reference Laboratory in Bristol, $\mathrm{UK}^{27,28}$.

Nucleic acids in maternal plasma are also useful in the detection of maternal complications of pregnancy such as pre-eclampsia, a life threatening disorder and intrauterine growth retardation (IUGR). In a longitudinal study of 130 pregnant women using total DNA ( $\beta$-globin) and fetal DNA (SRY), Butt and co-workers detected higher levels of 3-globin and SRY genes in those pregnant mothers who went on to develop IUGR or pre- eclampsia, showing that FcNAs may be a useful way of predicting abnormal outcome of pregnancy $^{7}$. In addition to fetal DNA, fetal RNA could be detected in maternal plasma and this has opened up another approach for noninvasive prenatal diagnosis. Measurement of circulating fetal RNA has the advantage that it can be applied to all pregnancies irrespective of the fetal gender or polymorphisms between mother and fetus. Recent studies have shown that fetus-specific circulating RNA has greatly increased the number of markers that could be used for prenatal diagnosis and monitoring $^{29}$. Tsui et al., showed that the concentration of mRNA for corticotrophinreleasing hormone $(\mathrm{CRH})$ is increased 10-fold in pre-eclamptic women, which was related to the severity of pre-eclampsia ${ }^{30,}{ }^{31}$. These newly discovered entities may be implicated in the underlying etiology of the disorder as well as may be useful in the non-invasive diagnosis, treatment and follow-up.

An important aspect that has emerged from these studies on the use of fetal DNA and RNA in maternal plasma for prenatal diagnosis is the lack of assay standardization, wide differences in sample collection and preparations, as well as the lack of a proper external quality assurance scheme. Recently, the special noninvasive advances in fetal and neonatal evaluation network (SAFE) were established with funds from the European Union with the aim of implementing routine costeffective, noninvasive prenatal diagnostic methods $^{32}$.

\section{FcNAs in oncology}

Many genetic and epigenetic alterations such as allelic loss, microsatellite instability, point mutations, amplification, translocation, and gene promoter region hypermethylation are associated with the development of malignancy. As these genetic and epigenetic alterations in the tumors and cancers have also been detected in circulating DNA, the detection of them has provided a potential tool for the early diagnosis, monitoring, and prognosis of tumor cancer patients including gastrointestinal, breast, lung, brain and neck, urological, gynecological, and skin.

In spite of improvements in the surgical, radiotherapeutic and chemotherapeutic modalities used to treat the various forms of lung cancer, there is no validated screening method for it. There is an urgent need to develop a more sensitive molecular marker panel for lung cancer diagnosis, risk assessment and follow up of patients. Some investigators have shown that aberrant DNA 
methylation can be detected in the serum and plasma of lung cancer patients. Using tumor and matched serum and plasma DNA, investigators examined aberrant DNA methylation for several gene promoters and showed that in the majority of lung cancer patients hypermethylation can be detected $^{33-35}$. This suggests that circulating DNA may be able to identify individuals who are at risk of developing lung cancer. This approach could therefore be used for early detection, surveillance and management of lung cancer patients.

Prostate cancer is the most common male malignancy and the second leading cause of male cancer-related mortality. Serum prostate specific antigen (PSA) is currently the best clinical laboratory marker for the detection of prostate cancer. However, serum PSA levels are not specific for cancer and are elevated in many other clinical conditions such as benign prostatic hyperplasia $(\mathrm{BPH})$, prostatitis and other non malignant prostate disorders, resulting in reduced specificity and false positives for PSA lead to unnecessary biopsies and other interventions. Of greater concern, 20-30\% of prostate cancer patients have serum PSA levels within the reference range, resulting in under diagnosis of the disease. One of the most promising molecular markers reported in a recent study is the analysis of human telomerase reverse transcriptase (hTERT) mRNA by rt-qPCR technique. Patients with prostatitis showed lower plasma hTERT mRNA expression than prostate cancer patients with a sensitivity and specificity of $81 \%$ and $60 \%$ respectively for diagnosis of prostate cancer ${ }^{36}$. In another study, the median DNA levels and frequency of loss of heterozygosity $(\mathrm{LOH})$, specific microsatellite averation, were reported to be higher in prostatic cancer than in $\mathrm{BPH}^{37}$. A recent study results demonstrated that specific cDNA probes of frequently differentially expressed mRNA transcripts identified by averaged differential expression (ADE) and RT-PCR can be used for the detection of prostate cancer in blood and urine samples ${ }^{38}$. However, additional studies including more patients and exploring additional laboratory procedures are required to validate these results for future clinical applications.

Radiography used to detect breast cancer progression, have been limited particularly in the current era of earlier disease diagnosis. The most sensitive method for the identification of breast cancer progression at the time of patient diagnosis is histopathologic lymph node evaluation. However, $20-30 \%$ of node-negative breast cancer patients will subsequently develop recurrent disease. Therefore, breast cancer recurrence is a result of undetected metastasis present at the time of primary patient diagnosis and treatment. Direct assessment of small amounts of body fluids for circulating tumor cells using microscopy has been shown to be tedious. Bone marrow is the most common site for systemic relapse following breast cancer diagnosis. Therefore investigators evaluated tumor-associated methylated DNA markers in bone marrow aspirates plasma and paired serum samples for early-stage patients undergoing surgery for breast cancer applying qMS-PCR using a selective tumor-related gene panel for retinoic acid receptor32 (RAR-B2), $\quad \mathrm{O}^{6}$-methylguanine DNA methyltransferase (MGMT) and ras-associated domain family protein 1A (RASSF1A). The most frequently detected gene (DNA) hypermethylation marker was RASSF $1 \mathrm{~A}^{39,40}$.

Concordance was present between gene hypermethylation defected in bone marrow or serum samples, and matched-pair primary breast cancers. In another study, which evaluated a majority of patients with stage-IV breast cancer, circulating DNA containing LOH was readily found in patients' serum, whereas in almost none of the cases circulating tumor cells could be identified $^{41}$. In another study several molecular markers such as plasma DNA, glutathione-stransferase P1 (GSTP1) gene, RASSF1A, ataxia telangiectasia mutated (ATM) methylation status (ATMMS), carcino embryonic antigen mRNA (CEA mRNA) and prostate-specific membrane antigen mRNA (PSMA mRNA) in peripheral blood mononuclear cell (PBMC) and plasma samples from prostate cancer patients, breast cancer patients and from normal individuals were examined by using rt-qPCR and qMS-PCR ${ }^{42}$. The combination of DNA load and promoter methylation status identified $88 \%$ of prostate cancer patients and $54 \%$ of breast cancer patients. This study showed that plasma free circulating DNA (fcDNA) can be detected in cancer patients compared with diseasefree individuals, and suggested a new, noninvasive approach for early detection of cancer ${ }^{42}$. Some reported studies on other cancers such as melanoma and ovarian cancer patients also suggested that measurement of total fcDNA and $\mathrm{LOH}$ in plasma of patients may be useful for non invasive screening, monitoring and disease surveillance ${ }^{43-45}$.

\section{FcNAs and other diseases}

In situations other than fetal medicine and oncology including trauma, stroke, diabetes mellitus, and autoimmune disease, measurement of fcDNA and organ-specific RNA has also been found to be useful. Recent studies have shown that messenger RNA for rhodopsin in the circulation was 
significantly higher in patients with diabetic retinopathy and preliminary results suggest that it may be a useful test for the prediction of long-term diabetic retinopathy complication ${ }^{46}$. In patients presenting to the emergency department, fcDNA was found to be elevated within an hour of the injury and the concentration of plasma fcDNA is related to the severity of the injury ${ }^{47}$. Furthermore, measurement of DNA at the patient's time of admission was able to predict the outcome in terms of organ failure, acute lung injury, acute respiratory syndrome as well as death. Similarly, in patients presenting with stroke, measurement of $\beta$-globin DNA concentration was found to be higher and this was a good predictor of death as a result of the stroke $^{46,47}$.

\section{Conclusions}

Analysis of FcNAs in plasma and serum is conventionally done by rt-qPCR because of the low copy number of the target DNA and RNA. The application of MALDI-TOF mass spectrometry to PCR has enabled the detection of nucleic acids with great sensitivity. The development of the SAPER method led to achievement of one base specificity and with the combination of the SAPER method and MALDI-TOF mass spectrometry, it was possible to show noninvasive prenatal diagnosis of $\beta$-thalassemia, where there is a single base point mutation $^{48,49}$. The problem of low sensitivity has been approached by the use of QF-PCR, which is based on the application of highly polymorphic chromosome-specific short tandem repeats using fluorescent primers, and the products are analyzed using an automated DNA sequencer ${ }^{50}$. The main advantages of QF-PCR are its accuracy, speed, automation, and low cost. The investigators have introduced these techniques for the prenatal diagnosis of several other disorders and have shown that these methods are accurate and could reduce the need for amniocentesis or chorionic villus sampling. However, preanalytical and analytical aspects of this field remain to be standardized. With these rapid developments in molecular biology techniques, the applications of FcNAs in clinical medicine has advanced especially in fetal blood grouping, prenatal diagnosis and cancer which is expected to be revolutionized. Further developments in the next few years will determine the clinical applications of FcNAs in diagnosis and monitoring of diseases more efficiently and effectively.

\section{Acknowledgement}

The authors would like to thank Mr. Moniruzzaman Khan, Assistant Programmer, Medical College for Women and
Hospital, Uttara Model Town, Dhaka 1230, Bangladesh for helping with internet browsing and typing the manuscript.

\section{References}

1. Foreign \& Commonwealth Office (FCO) \& British Council, UK. DNA and after: 50 years of UK Excellence. London, FCO Science \& Technology Unit, 2003, pp 1 - 50.

2. Watson JD, Crick FHC. Molecular structure of nucleic acids - a structure for deoxyribose nucleic acid. Nature 1953; 171: 737-38.

3. Murray RK. The human genome project. In: Murray RK, Granner DK, Mayes PA, Rodwell VW (eds). Harper's Illustrated Biochemistry, $26^{\text {th }}$ ed. Boston, McGraw Hill, 2003, pp 633-38.

4. Giasuddin ASM, Mujibul Haq AM. Double-stranded deoxyribonucleic acid (dsDNA): The blue print of life. J Med Coll Women Hosp. 2006; 4: 101-04.

5. Couzin J. Breakthrough of the year: Small RNAs make big splash. Science 2002; 298: 2296-97.

6. Schachter B. The explosive silence of RNAi. Update (N Y Acad Sci Magazine, USA) 2007; (Jan/Feb): 6-9.

7. Swaminathan R, Butt AN. Circulating nucleic acids in plasma and serum: Recent developments. Ann N Y Acad Sci 2006; 1075: 1-9.

8. Swaminathan R, Butt AN. Circulating nucleic acids in plasma and serum: Recent developments. Ann N Y Acad Sci. 2006; 1075: 1-9.

9. Tan EM, Schur PH, Carr RI, Kunkel HG. Deoxyribonucleic acid (DNA) and antibodies to DNA in the serum of patients with systemic lupus erythematosus. J Clin Invest. 1966; 45: 1732-40.

10. Koffler D, Agnello V, Winchester R, Kunkel HG. The occurrence of single-stranded DNA in the serum of patients with systemic lupus erythematosus and other diseases. J Clin Invest. 1973; 52: 198-204.

11. Leon SA, Shapiro B, Sklaroff DM, Yaros MJ. Free DNA in the serum of cancer patients and the effect of therapy. Cancer Res. 1977; 37: 646-50.

12. Stroun M, Anker P, Maurice P, Lyautey J, Lederrey C, Beljanski M. Neoplastic characteristics of the DNA found in the plasma of cancer patients. Oncology 1989; 46: 318-22.

13. Lo YM, Patel P, Wainscoat JS, Sampietro M, Gillmer MD, Fleming KA. Prenatal sex determination by DNA amplification from maternal peripheral blood. Lancet 1989; 2: 1363-65.

14. Anker P, Jachertz D, Maurice PA, Stroun M. Nude mice injected with DNA released by antigen stimulated human $\mathrm{T}$ lymphocytes produce specific antibodies expressing human characteristics. Cell Biochem Funct. 1984; 2: 33-37.

15. Gahan PB, Wyndaele R, Mantell S, Boggetti B. Evidence that direct DNA uptake through cut shoots leads to genetic transformation of Solanum aviculare Forst. Cell Biochem Funct. 2003; 21: 11-17.

16. Rosi A, Guidoni L, Luciani AM, Mariutti G, Viti V. RNA-lipid complexes released from the plasma 
membrane of human colon carcinoma cells. Cancer Lett. 1988; 39: 153-60.

17. Lledó SM, Garcia-Granero E, Dasí F, Ripoli R, Garcia SA, Cervantes A, Alino SF. Real time quantification in plasma of human telom-erase reverse transcriptase (hTERT) mRNA in patients with colorectal cancer. Colorectal Dis. 2004; 6: 236-42.

18. Bianchi DW, Watagarana T, Lapaire O, Tjoa ML, Maron JL, Larrabee PB, Johnson KL. Fetal nucleic acids in maternal body fluids: An update. Ann N Y Acad Sci. 2006; 1075: 63-73.

19. Wataganara T, Peter I, Messerlian GM, Borgatta L, Bianchi DW. Inverse correlation between maternal weight and second trimester circulating cell-free fetal DNA levels. Obstet Gynecol. 2004; 104: 545-50.

20. Pan PD, Peter I, Lambert-Messerlian GM, Canick JA, Bianchi DW, Johnson KL.Cell-free fetal DNA levels in pregnancies conceived by IVF. Hum Reprod. 2005; 20 : 3152-56.

21. Lo YMD. Fetal DNA in maternal plasma: Progress through epigenetics. Ann N Y Acad Sci. 2006; 1075: 74-80.

22. Lo YM, Tein MS, Lau TK, Haines CJ, Leung TN, Poon PM, Wainscoat JS, Johnson PJ, Chang AM, Hjelm NM. Quantitative analysis of fetal DNA in maternal plasma and serum: Implications for noninvasive prenatal diagnosis. Am J Hum Genet. 1998; 62: 768-75.

23. Poon LLM, Leung TN, Lau TK, Chow KCK, Lo YMD. Differential DNA methylation between fetus and mother as a strategy for detecting fetal DNA in maternal plasma. Clin Chem. 2002; 48: 35-41.

24. Chim SSC, Tong YK, Chiu RWK, Lau TK, Leung TN, Chan LYS, Oudejans CBM, Ding C, Lo YMD. Detection of the placental epigenetic signature of the maspin gene in maternal plasma. Proc Natl Acad Sci USA 2005; 102: 14753-58.

25. Li Y, Zimmermann B, Rusterholz C, Kang A, Holzgreve W, Hahn S. Size separation of circulatory DNA in maternal plasma permits ready detection of fetal DNA polymorphisms. Clin Chem. 2004; 50: 1002-11.

26. Li Y, Di Naro E, Vitucci A, Zimmermann B, Holzgreve W, Hahn S. Detection of paternally inherited fetal point mutations for beta-thalassemia using size-fractionated cell-free DNA in maternal plasma. JAMA 2005; 293: 843-49.

27. Daniels G, Finning K, Martin P, Summers J. Fetal blood group genotyping: Present and future. Ann N Y Acad Sci. 2006; 1075: 88-95.

28. Finning K, Martin P, Daniels G. A clinical service in the UK to predict fetal Rh (Rhesus) D blood group using free fetal DNA in maternal plasma. Ann N Y Acad Sci. 2004; 1022: 119-23.

29. Tsui NBY, Chim SSC, Chiu RWK, Lau TK, Ng EKO, Leung TN, Tong YK, Chan KCA, Lo YMD. Systematic micro-array based identification of placental mRNA in maternal plasma: towards non- invasive prenatal gene expression profiling. J Med Genet. 2004. 41: 461-67.

30. Wong BCK, Chiu RWK, Tsui NBY, Chan KCA, Chan LW, Lau TK, Leung TN, Lo YMD. Circulating placental RNA in maternal plasma is associated with a preponderance of 5' mRNA fragments: implications for non-invasive prenatal diagnosis and monitoring. Clin Chem. 2005; 51: 1786-95.

31. Tsui NBY, Lo YMD. Placental RNA in maternal plasma: Toward noninvasive fetal gene expression profiling. Ann N Y Acad Sci. 2006; 1075: 96-102.

32. Hulten, M. The SAFE network of excellence. Clin Chem. 2005; 51: 7-11.

33. Pan H, Califano J, Ponte JF, Russo AL, Cheng K-h, Thiagalingam A, Nemani P, Sidransky D, Thiagalingam S. Loss of heterozygosity patterns provide fingerprints for genetic heterogeneity in multistep cancer progression of tobacco smokeinduced non-small cell lung cancer. Cancer Res. 2005; 65: 1664-69.

34. Xue X, Zhu YM, Woll PJ. Circulating DNA and lung cancer. Ann N Y Acad Sci. 2006; 1075: 154-64.

35. Wang Y-C, Hsu H-S, Chen T-P. Molecular diagnostic markers for lung cancer in sputum and plasma. Ann N Y Acad Sci. 2006; 1075: 179-84.

36. Dasi F, Martínez-Rodes P, March JA, Santamaria J, Martinez-Javaloyas JM, Gil M, Alino SF. Real-time quantification of human telomerase reverse transcriptase mRNA in the plasma of patients with prostate cancer. Ann N Y Acad Sci. 2006; 1075: 20410.

37. Müller I, Urban K, Pantel K, Schwarzenbach H. Comparison of genetic alterations detected in circulating microsatellite DNA in blood plasma samples of patients with prostate cancer and benign prostatic hyperplasia. Ann N Y Acad Sci. 2006; 1075: 222-29.

38. Bai VU, Kaseb A, Tejwani S, Divine GW, Barrack ER, Menon M, Pardee AB, Reddy GP-V. Identification of prostate cancer mRNA markers by averaged differential expression and their detection in biopsies, blood, and urine. Proc Natl Acad Sci. USA 2007; 104 : 2343-48.

39. Taback B, Giuliano AE, Lai R, Hansen N, Singer FR, Pantel K, Hoon DSB. Epigenetic analysis of body fluids and tumor tissues: Application of a comprehensive molecular assessment for early-stage breast cancer patients. Ann N Y Acad Sci. 2006; 1075: 211-21.

40. Chiu RWK, Chim SSC, Wong IHN, Lee CS, To KF, Tong JHM, Yuen RKC, Chan ASWS, Chan LYS, Yuen JWF, Tong YK, Ferlatte JF, Leung TN, Lau TK, Lo KW, Den YM. Hypermethylation of RASSF1A in human and rhesus placentas. Am J Pathol. 2007; 170: 941-50.

41. Schwarzenbach H, Müller V, Stahmann N, Pantel K. Detection and characterization of circulating microsatellite-DNA in blood of patients with breast cancer. Ann N Y Acad Sci. 2004; 1022: 25-32. 
42. Papadopoulou E, Davilas E, Sortiriou V, Georgakopoulos E, Georgakopoulou S, Koliopanos A, Aggelakis F, Dardoufas K, Agnanti NJ, Karydas I, Nasioulas G. Cell-free DNA and RNA in plasma as a new molecular marker for prostate and breast cancer. Ann N Y Acad Sci. 2006; 1075: 235-43.

43. Taback B, Hoon DS. Circulating nucleic acids in plasma and serum: past, present and future. Curr Opin Mol Ther. 2004; 6: 273-78.

44. Mori T, O’Day SJ, Umetani N, Martinez SR, Kitago M, Koyanagi K, Kuo C, Takeshima T-L. Predictive utility of circulating methylated DNA in serum of melanoma patients receiving biochemotherapy. J Clin Oncol. 2005; 23: 9351-58.

45. Kamat AA, Sood AK, Dang D, Gershenson DM, Simpon JL, Bischoff FZ. Quantification of total plasma cell-free DNA in ovarian cancer using real-time PCR. Ann N Y Acad Sci. 2006; 1075: 230-34.

46. Hamaoui K, Butt A, Powrie J, Swaminathan R. Concentration of circulating rhodopsin mRNA in diabetic retinopathy. Clin Chem. 2004. 50: 2152-55.

47. Lam NYL, Rainer TH, Chan LYS, Joynt GM, Lo
YMD. Time course of early and late changes in plasma DNA in trauma patients. Clin Chem. 2003; 49: 128691.

48. Ding C, Cantor CR. A high-throughput gene expression analysis technique using competitive PCR and matrix-assisted laser desorption ionization time-offlight MS. Proc Natl Acad Sci USA 2003; 100: 305964.

49. Ding C, Chiu RWK, Lau TK, Leung TN, Chan LC, Chan AYY, Charoenkwan P, Ng ISL, Law H-Y, Ma ESK, Xu X, Wanapirak C, Sanguansermsri T, Liao C, Ai MATJ, Chui DHK, Cantor CR, Lo YMD. MS analysis of single-nucleotide differences in circulating nucleic acids: Application to non-invasive prenatal diagnosis. Proc Natl Acad Sci USA 2004; 101: 1076267.

50. Cirigliano V, Voglino G, Cañadas MP, Marongiu A, Ejarque M, Ordofiez E, Plaja A, Massobrio M, Todros T, Fuster C, Campogrande M, Egozeue J, Adinolfi M. Rapid prenatal diagnosis of common chromosome aneuploidies by QF-PCR. Assessment on 18,000 consecutive clinical samples. Mol Hum Reprod. 2004; 10: $839-46$. 